\title{
On the Relationship between Self-regulated Learning Components and L2 Vocabulary Knowledge and Reading Comprehension
}

\author{
Abbas Ali Zarei \\ Imam Khomeini International University, Qazvin, Iran \\ Email: aazarei@ikiu.ac.ir \\ Gamar Hatami \\ Alborz High Education Center, Qazvin, Iran
}

\begin{abstract}
In the past two decades, self-regulation has been the center of heated debate in educational psychology. The present study attempted to investigate the relationship between Iranian EFL learners' selfregulated learning components and vocabulary knowledge and reading comprehension .To fulfill this objective, a 60-item vocabulary and reading comprehension TOEFL test was administered to a sample of 250 male and female college students majoring in English Teaching, English Language Translation, and English Literature. The Persian version of "Self- regulation Trait Questionnaire" was administered to the same participants. Pearson correlation procedure was used to analyze data. Results indicated that the correlation between selfregulated learning components: planning, self -checking, effort and self-efficacy gave mixed results. That is to say, two of the correlation coefficients, self -checking and effort were significant while the other two, planning and self-efficacy, were non-significant.
\end{abstract}

Index Terms -EFL, self-regulated learning, vocabulary, reading comprehension

\section{INTRODUCTION}

In the past 20 years, many studies have been conducted on self-regulated learning theories and its components. Selfregulated learning (SRL) has been known as an appreciated topic in academic psychology for two decades. Moreover, a strong desire among researchers has also led to the development of an appropriate theory of self-regulated learning.

During the recent years, many interesting studies have been done on the foundation, nature, and improvement of how learners can regulate their own learning to facilitate the learning process, yet the psychological mechanisms engaged in self-regulation have remained incompletely understood. Boekaerts (1996) believes that many studies have shown an interest in developing a self-regulated learning theory and considerable research has been generated, but the concept is defined too broadly and its basic foundation poorly understood up to now.

Examination of our current understanding of the relationship between self-regulation and vocabulary knowledge and reading comprehension generated from prior studies indicate a need for a profound understanding of this relation. Although this important concept has been found to be effective in academic attainment, research has not provided sufficient evidence to establish unambiguous relationship between it and language components. The main objective of this study is, therefore, to investigate the relationship between self-regulation and vocabulary knowledge and reading comprehension. It aims to answer the following questions:

1. Is there any relationship between self-regulated learning components and vocabulary knowledge in Iranian EFL context?

2. Is there any relationship between self-regulated learning components and reading comprehension in Iranian EFL context?

\section{REVIEW OF RELATED LITERATURE}

Based on Zimmerman and Bandura (1994), self-regulation is a concept that refers to learners' self-generated ideas, actions and feelings which are oriented systematically toward achievement of educational goals. Zimmerman (2000) states that "self-regulated learning engages students' active participation in learning from the metacognitive, motivational and behavioral point of view" (p.66).

Baumeister and Vohs (2008) state that self-regulation refers to a person's ability to change his/her behavior. The quality and existence of these actions would alter in relation to some goals, ideals and norms no matter whether their stem would have public or internal anticipation. In general, human behavior flexibility and adaptability will increase during self-regulation process. This flexibility enables learners to regulate their performance to a broad range of 
situational or public requirements they encounter in their daily life experience. Self-regulation is promoted through effects of goals on motivation, learning, self-efficacy, and self-evaluations of progress (Bandura, 1997).

Zimmerman (1989) argues that studies on learning strategies show developmental analyses of learners' use of strategies. In general, self-regulation is used more effectively by adolescents than by children, and is more obvious among higher achieving than lower achieving learners.

Boekaerts (1996) asserts that there are also two important parallel aspects regarding self-regulation of the components of motivational and cognitive repertoire with a reciprocal relationship between them. These aspects focus on three levels: 'goals, strategy use and domain specific knowledge'.

Bandura (1986) believes that competent self-regulative behavior is not attained by an 'act of will'. It demands special abilities in self-leading and self-motivation. Some researchers have conducted research on students' use of selfregulatory processes and its quality and quantity has shown a high correlation with academic attainment as well as with standardized test scores. (Zimmerman \& Pons, 1986).

Schunk and Zimmerman (2003) claim that like other processes, self-regulation (or self-regulated learning) changes across the life span. A weak spot about self-regulated learning (SRL) is that little research has been conducted on learners after they leave their formal schooling, yet the available data does not seem to be inadequate follow up. There are some questions about how individuals regulate their family life, finances, work schedules, and so on. A fruitful area to investigate and one which has attracted much attention is how grownups use self-regulation to balance their professional and personal lives, how they use goal setting, self-evaluation of the process, monitoring of time spent, and other methods and skills; and which ways are most efficient to teach these strategies.

Zimmerman (1998) defines self-regulation processes as a kind of self-directed feelings, thoughts and behaviors for achieving academic goals. He continues that, self-regulated learning involves goal-directed actions that students modify, sustain and instigate. He also believes that learners can practice this strategy for their academic studies.

Zimmerman (2002, p.67) organized self-regulated processes under three 'cyclical phases', namely, 'forethought phase', 'performance phase', and self-reflection phase'. 'Forethought phase, or proactive phase, pertains to beliefs and processes that occur before learners' attempts to learn; it involves two main levels: 'task analysis', which by itself consists of goal setting and strategic planning, and 'self-motivation', which is rooted in students' perceptions and learning beliefs. The 'performance phase' also contains two sub-phases. 'self-control' refers to choosing methods during forethought phase, and 'self-observation' is the 'self-record' of personal events or self-experimentation to finding the cause of such events. The 'self-reflection phase' consists of two major stages: 'self-judgment' and 'selfevaluation'. These levels refer to comparing one's self presentation against some principles and rules.

According to Zimmerman (2002), self-regulated learning is an activity that learners make for themselves in a proactive manner not a hidden event that occurs to them in response to teaching. In other words, it is a self-generated process in which students can change their own mental capability into educational aims. So, it cannot be an academic performance skill or a mental ability. In this situation 'proactively' can be defined as the awareness of student's own limitations and strengths.

Based on Boekaerts' (1999) model, 'self-regulated learning' has a powerful construction that allows researchers:

Firstly, to describe the various components that are part of successful learning; secondly, to explain the reciprocal and recurrent interactions that accrue among the different components, and thirdly to relate learning and achievement directly to the self, that is to a person's good structure (P.447)

Boekaert's (1999) three layer model of SRL in its innermost layer provides some information about the typical way in which students learn and describe the importance of their self-regulation process and its quality. The middle layer represents how the learners regulate learning processes based on their own knowledge and ability. The outermost layer deals with regulation of the self; this contains students' ability to define ongoing and upcoming actions in the light of their own needs, expectations and wishes.

It is generally believed that elf-regulation strategies can be learned, taught and controlled. In general, the learners who are engaged in the self-regulated process must have some qualities that others lack. In fact, studies have revealed that such characteristics differentiate self-regulated learners from those who do not have such qualities (Zimmerman, 1998, 2002; Winne, 1995; Oettiengen, et al., 2000; Perry \& Vandekamp (2000).

A number of studies have investigated self regulated learning. Magno (2011) examined the predictive validity of the academic self-regulated learning scale (A-SRL-S). In his study, Grade Point Average (GPA) was used as the orientation and was found to be significantly related to each of the A-SRL-S factors. The participants of the study were 2052 Filipino College students in the Philipines, whose age range was from 16 to 20 years. The study emphasized the importance of developing students' use of self-regulatory strategies as part of instruction to help students achieve better performances.

Kozlowski and Bell (2006) examined the integrated and independent effects of goal setting and attainment orientation views on learners' self-regulatory activity. The participants of this study were 524 students. The result showed that goal content, goal proximity activities and goal frame have a significant influence on self-regulation. It was also revealed that goal content has the highest impact. The compatible learning and content relative to congruent performance frame and content was very helpful to learners' self-regulatory activity, incongruent combinations of goal 
frame and content were better than frames and content and congruent performance, and the impact on incongruent grouping was asymmetrical.

Cleary and Zimmerman (2001) studied 43 adolescent male students to see how much their level of skill in playing basketball affects their self-regulatory forethought, the sense of satisfaction and self-reflection processes regarding their free-shooting practice. Their findings confirm that inefficient choice of learning strategies and nonspecific goals of learning strategies and non-experts' lower self-efficacy insights hinder their promotion as free-throw shooters.

Young (2005) provided experimental evidence for the theoretical relationships among cognitive evaluation theory and achievement goal theory and self-regulated learning strategies in the classroom environment. The participants were a sample of 257 learners who responded to a four-page self-report questionnaire. Each of the major variables had a scale along with individual items ordered randomly within the scale. The results showed that artificial learning tactics were linked to extrinsic motivation, but intrinsic motivation showed a deeper cognitive and metacognitive strategy usage.

An exploratory research was done by Endedijk, Vermunt, Brekelmans and Broke (2006) to measure self-regulated learning by the quality of instruments in a complex learning environment. They used four developmental instruments, portfolio interview, and task-based questionnaire. The results showed that promoted task based questionnaire was an efficient instrument for use for measuring self-regulated learning in the context of teacher education. Another finding was that portfolio interview and portfolio cannot measure every aspect of self-regulated learning.

A study conducted by Hong, Peng and Rowell (2009) tested the differences in the reported homework by learners' incentive, homework value and metacognitive strategy use during completing homework among two grades, gender and three attainment levels. It also examined six homework self-regulation constructs (intrinsic value, persistence, utility value, planning, self-checking and effort). The participants were 407 eleventh and 330 seventh graders from a metropolitan city in china. Results showed a decline in homework self- regulation from middle to high school although the learners' rate of utility value and effort were high, self-checking and self-regulation were low. The study also showed that homework experiences are positively related to learners' use of learning strategies and to their responsibility for their educational outcome.

The above-mentioned studies have shed some light on the little explored area of self-regulation. However, there are still many gaps that remain to be filled. In an attempt to partially fill the existing gap, the present studies explores the relationships between self-regulation and L2 vocabulary and reading comprehension ability.

\section{METHOD}

\section{participants}

In the present study, a sample of 250 college students majoring in TEFL, English Language Translation, and English Literature at Alborz University, Imam Khomeini International University, Kar University, and I Takestan slamic Azad University, Qazvin, Iran were selected. The initial number of participants was then reduced to 211 after the administration of the TOFEL Test and self-regulation questionnaires, 39 participants were excluded because they did not answer all three tests.

\section{Instrumentation}

In this research, the "Self- regulation Trait Questionnaire" developed by O'Neil and Herl (1998), was administered to participants. It consisted of 32 items and every 8 items measured a different construct: Planning, Self -checking, Effort and self-efficacy. In order to facilitate students' understanding, the translated version was utilized. To measure the participants' vocabulary and reading comprehension knowledge, two already established vocabulary and reading comprehension subtests of TOFEL were used.

\section{Procedures}

In order to correlate the participants' self-regulations with their vocabulary and reading comprehension knowledge, the following procedures were followed: first, the TOEFL vocabulary and reading comprehension subtests were administered to the participants to measure their vocabulary and reading comprehension knowledge. The test contained 30 vocabulary and 30 reading comprehension items. Then, the Self-regulation Trait Questionnaire was given. In this Questionnaire, Likert Scale was used and the participants were asked to choose from among five alternatives: 1) almost never 2) Seldom 3) Sometimes 4) often 5) Almost always. Finally, the correlations between these variables were checked. Because this questionnaire was used for the first time in Iran by Dehghan, Mirhassani and Akbari (2006), the researchers translated "Self- regulation Trait Questionnaire" into Persian. They checked the reliability of the Questionnaire using cronbach alpha, the results showed alpha $=.79$. To check the construct validity of all the 32 items of the Persian version of the mentioned Questionnaire, they also did a factor analysis using principal axis factoring. 28 of 32 items fulfilled the criteria mentioned in Salimi (2001, P.42). According to salimi, "the criteria for including an item in a factor are that its loading on that factor be greater than .25 and greater than its loading on either of the other factors". So, they omitted the items that failed to load on the relevant factors for the main research. It was, therefore, assumed that the Persian version of Self- regulation questionnaire enjoys satisfactory reliability and validity. The obtained data were analyzed using the Pearson Correlation procedure.

\section{Results}


The first research question sought to investigate if there was any significant relationship between vocabulary knowledge and self-regulated components: Planning, Self-Check, Effort and Self-Efficacy. In order to answer to this question, the Pearson correlation procedure was used. The results are summarized in Table 1.

TABLE 1.

CORRELATION BETWEEN SELF-REGULATED LEARNING COMPONENTS AND VOCABULARY

\begin{tabular}{|c|c|c|c|c|c|}
\hline & & Planning & Self-Check & Effort & Self-Efficacy \\
\hline \multirow{3}{*}{ Vocabulary } & Pearson Correlation & .00 & .03 & .01 & .09 \\
\hline & Sig. (2-tailed) & .97 & .63 & .86 & .18 \\
\hline & $\mathrm{N}$ & 21 & 21 & 21 & 21 \\
\hline
\end{tabular}

Table 1 shows that there is no significant relationship between vocabulary and planning $(\mathrm{R}(209)=.00, \mathrm{P}=.97>.05)$. There is also no significant relationship between vocabulary and self-check $(\mathrm{R}(209)=.03, \mathrm{P}=.63>.05)$. The relationships between vocabulary and effort $(\mathrm{R}(209)=.01, \mathrm{P}=.86>.05)$ and vocabulary and self-efficacy $(\mathrm{R}(209)$ $=.09, \mathrm{P}=.18>.05)$ are not significant either.

Another Pearson correlation was used to investigate relationships between reading and self- regulated components: planning, self-check, effort and self-efficacy. The results are summarized in Table 2.

TABLE 2.

CORRELATION BETWEEN SELF-REGULATED LEARNING COMPONENTS AND VOCABULARY KNOWLEDGE

\begin{tabular}{|l|l|l|l|l|l|}
\hline \multicolumn{2}{|c|}{} & Planning & Self-Check & Effort & Self-Efficacy \\
\hline \multirow{3}{*}{ Reading } & Pearson Correlation & .10 & $.14^{*}$ & $.17^{*}$ & .08 \\
\cline { 2 - 7 } & Sig. (2-tailed) & .14 & .04 & .01 & .24 \\
\cline { 2 - 7 } & N & 211 & 211 & 211 & 211 \\
\hline \multirow{2}{*}{ *. Correlation is significant at e 0.05 level (2-tailed). }
\end{tabular}

As it can be seen from Table 2, there is no significant relationship between reading and planning $(\mathrm{R}(209)=.10$, $\mathrm{P}$ $=.14>.05)$, but there is a significant positive relationship between reading and self-check $(\mathrm{R}(209)=.14, \mathrm{P}=.04$ $<.05)$.There is also a significant relationship between reading and effort $(\mathrm{R}(209)=.17, \mathrm{P}=.01<.05)$, whereas the relationship between reading and self-efficacy $(\mathrm{R}(209)=.08, \mathrm{P}=.24>.05)$ is not significant.

\section{DISCUSSION}

It may be surprising that the findings of this study are not in line with many previous studies (e.g., Magno, 2011; Kistantas, Steen, Huie, 2009; Kozlowski, \& Bell, 2011; Oettingen, Honig, \& Collwitzer, 2000; Young, 2005; Hong, Pang \& Rowell, 2009). Although they did not investigate the relationship between self-regulated learning strategies and vocabulary and reading comprehension specifically, their findings reveal that there is a significant positive relationship between self-regulated learning strategies and learners' attainment. The important point is that reading comprehension and vocabulary knowledge are two major language components. So, we can conclude that if there is a positive relationship between self-regulated learning strategies and language proficiency, the self-regulated learning strategies ought to have a direct relationship with reading comprehension and vocabulary knowledge.

Some other studies have been done on students' self-regulated learning strategies and English reading comprehension. One such study conducted by Pratontep and Chinvonno (2008) aimed to investigate learners' self-regulated learning strategies in an Extensive Reading program. Findings revealed that there were significant differences between learners' reading mean scores after 10 weeks of training in self-regulated strategies. Another study conducted by Mirhassani, et al., (2007) on the relationship between self-regulated components and language proficiency demonstrated that there was a significant relationship between language proficiency and self-regulatory components. In addition, Shang (2010) provided empirical support for a significant positive relationship between perceived self-efficacy and using reading strategies although there was no significant relationship between reading strategies and reading attainment.

A number of factors might have contributed to the results obtained in this study. These factors might make the results of the study different from the ones mentioned above. One factor may be the learning context; unlike this study that was conducted in EFL context and with intermediate level learners, majoring in English language literature, English language translation, and English language teaching, they were conducted either in ESL or first language contexts. Furthermore, some the afore-mentioned studies considered gender as a variable, while it was not taken into consideration in this study. Some other differences may be attributable to the following factors:

One of the possible reasons for such differences may be partially attributable to the cultural differences leading to different abilities of the participants. Our participants included the combination of Persian and Turkish students. Alagozlu (2007) claims that Turkish EFL students are not strong enough to express their feelings and thoughts, especially in a foreign language context. They refuse expressing their thoughts, because they are afraid that their ideas may not to be appreciated. This problem originates from the system of conventional education, which provides readymade information without any questions. In such contexts, students prefer to be quiet than lose their face. The Iranian context, by culture and attitude, falls into the same category.

There are some other reasons for such differences; for example, some people feel like what they achieve is never quite good enough. They often feel they have to achieve more than 100 percent in everything they do, otherwise, they 
feel bad about themselves and see themselves as a failure. Perfectionists spend all their time trying to do their best but end up feeling that they never quite succeed. So they might feel whatever they did was not good enough even though it was! Maybe we need to consider each group with their levels of expectation to analyze their answers on the survey.

For many, it is more desirable to have better answers and look good, they could be called euphemistic. By answering each positive characteristic that could make one believe that they truly are what they want to be. People may avoid saying negative things about themselves. It always feels better to confess being organized than being messy, for instance. Sometimes their answers relate to their perceptions about who they are. They are less likely to believe their negative habits are real.

In addition to that, sometimes people are trapped in a situation where there is no reward and they just carelessly answer multiple choice questions without thinking about the concept, or they are in a hurry and simply do not care.

\section{CONCLUSION}

Based on the findings of the present study, it may be concluded that there is no significant relationship between selfregulated components and vocabulary knowledge, but the relationships between the same components and reading comprehension knowledge of Iranian EFL learners were mixed.

The findings of the present study may have implications for teachers, learners, and materials developers. A clear understanding of the nature of the relationships between vocabulary and reading comprehension on the one hand, and the components of self-regulated learning, on the other may change teachers' and students' views toward the importance of teaching and learning self-regulation skills and their use in every domain of daily life. Teachers must provide learners with the domain, instrumental support and strategy knowledge they need to operate independently. Students can benefit from learning self-regulated skills by incorporating them into their learning processes, which may help them, become independent and responsible in their own learning.

\section{REFERENCES}

[1] Alagozlu, N. (2007). Critical thinking and voice in EFL writing. Asian EFL Journal, 9(3), 118- 136.

[2] Bandura, A. (1986). Social foundations of thought and action. Englewood Cliffs, NJ: Prentice-Hall.

[3] Bandura, A. (1994). Self-efficacy, In VS Ramachaudran. Encyclopedia of Human Behavior, 4, 71-81.

[4] Bandura, A. (1997). Self-efficacy: The exercise of control. New York: Freeman.

[5] Baumeister R. F., \& Vohs,K.D. (2008). SELF-regulation, Ego Depletion, and Motivation. Social and Personality Psychology Compass, 1, 1-14.

[6] Boekaerts, M. (1996). Self-regulated learning at the junction of cognition and motivation. European Psychologist, 1(2), 100112.

[7] Boekaerts, M. (1999). Self-regulated learning: Where we are today. International Journal of educational research, 31(6), 445457.

[8] Cleary, T. J., \& Zimmerman, B. J. (2001). Self-regulation differences during athletic practice by experts, non-experts, and novices. Journal of Applied Sport Psychology, 13(2), 185-206.

[9] Dehgan, M., Mirhassani , A. \& Akbari ,M. (2006). The relationship between Iranian EFL Learners' Goal-oriented and Selfregulated Learning and Their Language Proficiency. Unpublished MA Thesis. Tarbiat Modares University, Iran.

[10] Endedijk, M. D., Vermunt, J. D., Brekelmans, M., Den Brok, P., \& Verloop, N. (2006). Measuring self-regulation in complex learning environments. Paper presented at the ICO Toogdag, Amsterdam.

[11] Kitsatas, A, Steen, Steen, S., \&Huie, F. (2009). The role of self-regulated strategies and goal orientation in predicting achievement of elementary school children. International Electronic Journal of Elementary Education, 2(1), 65-81.

[12] Kozlowski, S. W., \& Bell, B. S. (2006). Disentangling achievement orientation and goal setting: Effects on self-regulatory processes. Journal of Applied Psychology, 91(4), 900-916.

[13] Hong, E., Peng, Y., \& Rowell, L. L. (2009). Homework self-regulation: Grade, gender, and achievement-evel differences. Learning and Individual Differences, 19(2), 269-276.

[14] Magno, C. (2011).The predictive validity of the academic self-regulated learning scale. The international Journal of Educational Psychological Assessment, 9(1), 48-56.

[15] Mirhasani, A., Akbari, R., \& Dehgan, M. (2007). The relationship between Iranian EFL Learners' Goal-oriented and Selfregulated Learning and Their Language Proficiency. Journal of Teaching English Language and Literature Society of Iran (TELLSI), 1( 2), 1-15.

[16] Oettingen, G., Hönig, G., \& Gollwitzer, P. M. (2000). Effective self-regulation of goal attainment. International Journal of Educational Research, 33(7), 705-732.

[17] O'Neil Jr, H. F., \& Herl, H. E. (1998). Reliability and validity of a trait measure of self-regulation. Annual meeting of the American Educational Research Association, Diego, CA.

[18] Pratontep, C. \& Chinvonno, A. (2008). Self-regulated learning by Thai university students in An EFL Extensive Reading Program. Retrieved December 11, 2011, from: www.manusya.journals.chula.ac.th/files/.../Chitchon_p104-124.pdf

[19] Perry, N. E., \& VandeKamp, K. J. (2000). Creating classroom contexts that support young children's development of selfregulated learning. International Journal of Educational Research, 33(7), 821-843.

[20] Salimi, E. A. (2001) On the Relationship between Impulsivity/ Reflectivity cognitive style and performance on TMU English Exam. MA Thesis. Tarbiat Modares University.

[21] Schunk, D. H., \& Zimmerman, B. J. (2003). Self-regulation and learning. Handbook of Psychology. 7, 59-78. 
[22] Winne, P. H. (1995). Self-regulation is ubiquitous but its forms vary with knowledge. Educational Psychologist, 30(4), 223228.

[23] Young, M. R. (2005). The motivational effects of the classroom environment in facilitating self-regulated learning. Journal of Marketing Education, 27(1), 25-40.

[24] Zimmerman, B. J., \& Pons, M. M. (1986). Development of a structured interview for assessing student use of self-regulated learning strategies. American Educational Research Journal, 23(4), 614-628.

[25] Zimmerman, B. J. (1989). A social cognitive view of self-regulated academic learning. Journal of Educational Psychology, 81(3), 329-339.

[26] Zimmerman, B. J. \& Bandura, A. (1994). Impact of self-regulatory influences on writing course Attainment: The role of selfefficacy beliefs and personal goal setting. American Educational Research Journal, 31, 845-862.

[27] Zimmerman, B. J. (1998). Academic studding and the development of personal skill: A self- regulatory perspective. Educational psychologist, 33(2-3), 73-86.

[28] Zimmerman, B. J. (2000). Attaining self-regulation: A Social Cognitive Perspective. Handbook of self-regulation, 13-41.

[29] Zimmerman, B. J. (2002). Becoming a self-regulated learner: An overview. Theory into Practice, 41(2), 64-70.

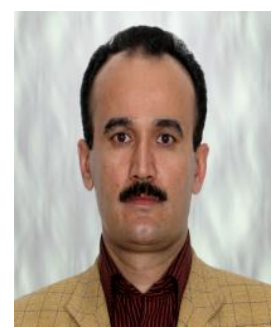

Abbas Ali Zarei is a PhD holder in TEFL. He is a member of academic staff at Imam Khomeini International University in Qazvin, Iran. He has authored 14 books and translated four others. He has also had 21 articles published.

Gamar Hatami is an MA graduate in TEFL. She is an experienced teacher who has taught at various language institutes. She now runs her own language institute in Qazvin, Iran. 